\title{
Examining the production parameters of European perch (Perca fluviatilis) juveniles under different lighting conditions
}

\author{
Áron Molnár ${ }^{1,2}$ - László Kovács ${ }^{1,2}$ - Dávid Homoki ${ }^{1,2}$ - Dániel Minya ${ }^{1,2}$ - Milán Fehér ${ }^{1}$ \\ ${ }^{1}$ University of Debrecen, Faculty of Agricultural and Food Sciences and Environmental Management, Department of Animal Husbandry, \\ Debrecen \\ ${ }^{2}$ University of Debrecen, Doctoral School of Animal Science \\ molnar.aron@agr.unideb.hu
}

\begin{abstract}
SUMMARY
European perch (Perca fluviatilis) is a native predatory fish in Hungary, and a promising new species of fresh water aquaculture nowadays. The European perch can be characterized by a high stress sensitivity during the intensive rearing, thus the optimization of environmental conditions has significant importance in the early life stages of fish. The aim of our study was to determine whether the light intensity and darkening of the water by humic acid affect the survival and growth performance of European perch juveniles. The experiment lasted for 28 days. Rectangular aquariums were arranged in 3 lines, the test environment consisted of 24 units. The experiment was set up with 10-10 fish per aquarium, total of 240 individuals. The average wet body weight of the fish at the start of the experiment was 1.69 grams. During the experiment, 6 treatments in 4 replicates were set up. In the first row, we set up 305.6 \pm 66.0 LUX (L), in the second row $118.0 \pm 24.4$ LUX (C), and in the third row (D) 17.0 8.6 LUX illumination was set up. In each row the water of four aquariums were darkened by the addition of humic acid $(H)(L, L H, C, C H, D$, and DH). At the end of the experiment high survival rate was observed in all treatments. Examining the survival rate, the best results were found in the strongly illuminated treatments $(L ; L H-S R \%=100 \pm 0.00)$. The observed mortality was caused by cannibalism. Regarding the individual body weight, the best results were shown by the treatments where the aquariums were illuminated with lower light intensity (C: $4.66 \pm 0.33$ grams) and the aquarium water was darkened by humic acid (CH: $4.93 \pm 0.15$ grams). The results of the $C$ and $C H$ groups were significantly better compared to the other treatments, however, they did not differ statistically from each other. The darkening of the water had a positive effect on the individual body weight of fish reared under full light (L: $3.73 \pm 0.28$ grams; LH: 4.33 \pm 0.28 grams), whereas in the case of fish reared in the lowest illumination, the addition of humic acid did not affect the results (D: $3.78 \pm 0.15$ grams; DH: $3.80 \pm 0.26$ grams). In case of SGR (C: 3.64\%/day and CH: 3.74\%/day) and FCR (C: $0.84 \mathrm{~g} / \mathrm{g}$ and CH: $0.78 \mathrm{~g} / \mathrm{g}$ ) the best results were obtained by the $C$ and $\mathrm{CH}$ treatments, also.
\end{abstract}

Keywords: European perch; light intensity; water turbidity; humic acid; intensive recirculation system (RAS)

\section{INTRODUCTION}

European perch (Perca fluviatilis) is a popular fish species among anglers and it has a significant market demand in Europe (Craig, 2000; Järv et al., 2013; Couture \& Pyle, 2015; Skov et al., 2017; Lyach \& Remr, 2019). It can be characterized by slow growth, however it has an excellent meat quality. Perca fluviatilis has large eyes for perfect food detection, its green colour body covered with small scales, with stripes on the side. The fish reaches sexual maturity relatively late, the propagation under artificial conditions is difficult. The phenomenon of cannibalism can be observed at younger life stages (Couture \& Pyle, 2015), which is confirmed by our own experience. During the intensive rearing it shows high stress sensitivity (Acarete et al., 2004; Orban et al., 2005; Strand et al., 2007a).

Considering the lifestyle of European perch in natural waters, it often moves in shoal and its diet consists mostly of smaller fish. It shows increased feeding activity during the period of light changes like other predatory fish species and has a top-down regulating effect on the ecosystem (Couture \& Pyle, 2015).

European perch is a diurnal predatory fish species, therefore light conditions are extremely important consideration of feeding behaviour (Craig et al., 1977; Tamazouzt et al., 1998; Boeuf et al., 1999; Tamazouzt et al., 2000; Strand et al., 2007b). The predator in decent light conditions can detect and capture its potential preys more efficient (Brüning et al., 2016). During the aquaculture production, the optimization of environmental conditions is extremely important in the early life stages of fish (Pickering, 1993). Modification of light conditions and tank colour during the intensive rearing are also considered a good option for better food visibility, which has a positive effect on the production parameters in RAS. The aim of the experiment was to determine whether the light intensity and darkening of the water by humic acid affect the survival and growth performance of European perch juveniles.

European perch belongs to the order of Perciformes. A large number of fish species represent this order; therefore, several studies investigates their stress sensitivity. A research team investigated Arripis truttaceus stress responses caused by capture and captivity. They measured the plasma cortisol level of the fish after captured by hook immediately $(8+5$ $\mathrm{ng} \mathrm{ml}^{-1}$ ) and also under captivity. Peak plasma cortisol concentration in fish during transport was $161 \pm 31$ $\mathrm{ng} \mathrm{ml}{ }^{-1}$ after two hours of capture. Half of the experimental fish were kept in large pools, while the other part was kept in narrow swim tunnels with a continuous flow of water. The swim tunnel caused increased plasma cortisol, 2 hours after release $(112 \pm 31$ $\mathrm{ng} \mathrm{ml}^{-1}$ ). This value increased to $233 \pm 55 \mathrm{ng} \mathrm{ml}^{-1}$ after 2 days. The fish cortisol levels returned to normal level within 3 days after capture in large pools. 
In summary, Arripis truttaceus can be kept in large tanks with minimal stress. However, too high stocking density can induce severe stress responses, hence it is not advisable to restrict their living space, consequently such circumstances are inadequate for investigating the physiology of this species (Davidson et al., 1997).

A research group studied the effect of light at night on the production of melatonin and cortisol in European perch. They were exposed to four different light intensities during the night, $01 \mathrm{~lx}$ was the control group, 1 $\mathrm{lx}, 10 \mathrm{~lx}$ and finally $100 \mathrm{~lx}$. Melatonin and cortisol concentrations were measured from water samples, every 3 hour during a 24 hour period. According to the results the melatonin rhythm of the fish was impaired significantly due to the artificial light, even the lowest light intensity inhibited melatonin production. However, artificial light had no effect on cortisol levels in fish. In their opinion, even the slightest artificial light can disturb the biorhythm of fish, but at the same time their stress levels are not affected (Brüning et al., 2015).

In addition to the stress sensitivity of European perch, rearing it in an intensive system at an early age could be complicated due to its eating habits. According to one study, high mortality in perch aquaculture production can be reduced by supplementing commercial dry feed with minced, less valuable fish (Härkönen et al., 2017).

In our experiment, humic acid was chosen mainly because of the darkening of the water, but when examining its biological composition, it also has several advantageous properties, as well as a completely natural material, so it is also environmentally friendly to use.

Humic materials are often found on the surface of the earth, in both terrestrial and aquatic environments (Kerndorff \& Schnitzer, 1980). Humic acid is the part of the humus that dissolves in aqueous sodium hydroxide in a process and then precipitates by acidification of the alkaline extract (Haworth, 1971). Humic acids are a class of compounds derived from the decomposition of organic matter, primarily plants. Its effect is present in many areas. Humic acid has a number of beneficial effects, such as antibacterial, antiviral and anti-inflammatory, improves the immune system and stress management (Islam, 2015).

Humic substances are formed in the millennial decomposition processes of plant-derived biomass, during the humification of plants. The family of humins includes biologically active and highly valuable humic acids and fulvic acids, These organic macromolecules with special properties can be extracted from peat from carboniferous vegetation (Rupiasih \& Vidyasagar, 2005).

\section{MATERIALS AND METHODS}

The experiment lasted for 28 days and was carriedout in the aquarium system of the Fish Biology Laboratory at the University of Debrecen. The rectangular aquariums with a water volume of 12 litres were arranged in 3 rows, the test environment consisted a total of 24 units. For the mechanical and biological filtration of the water individual sponge filters were used. The test was set up with 10-10 perch juveniles in each aquarium, total of 240 fish. Prior to the experiment, the wet body weight $(1.69 \pm 0.04$ grams $)$ and body length of the fish were determined individually using a two-decimal digital scale and millimetre paper. Standard body length data were evaluated using Image $\mathbf{J}$ software.

During the experiment, 6 treatments in 4 replicates were set up. In the first row of the aquarium system experimental fish were kept at 305.6 \pm 66.0 LUX illumination with ( $\mathrm{LH})$ and without humic acid addition (L). In the second row, the aquariums were covered with green net and fish were kept at 118.0 \pm 24.4 LUX illumination with $(\mathrm{CH})$ and without humic acid addition (C). In the third row, the aquariums were totally covered and juveniles were kept at 17.0 \pm 8.6 LUX illumination with (DH) and without humic acid addition (D).

The dissolved oxygen concentration of the water $(88.94 \pm 4.43 \%)$ and the water temperature $(22.9 \pm 1.3$ $\left.{ }^{\circ} \mathrm{C}\right)$ were measured daily using a HACH LANGE HQ30d device in 2-2 and 1-1 randomly selected aquariums per row, respectively. The optimal water temperature of $22^{\circ} \mathrm{C}$ was set in the aquarium system. The duration of illumination was 14 hours per day (06 to 20 hours).

The turbidity and $\mathrm{pH}$ of the water and the various forms of nitrogen in the water (ammonia, nitrite and nitrate) were checked weekly using a HACH LANGE DR3900 spectrophotometer from samples taken from 3-3 randomly selected aquariums. For humic acidtreated aquariums, the water turbidity was $3.78 \pm 0.15$, which was used as a reference for 4 weeks. The light intensity was determined using a PKT-5065 LUXMETER, also once a week.

Daily feed portion was determined at $2.5 \%$ of the initial biomass. In the experiment Aqua Garant Aqua Start $1 \mathrm{~mm}$ sinking feed (Crude protein: $60 \%$, crude fat: $15 \%$, crude ash: $14.5 \%$, crude fibre: $1.5 \%$, calcium $2.20 \%$, phosphorus $2.30 \%$ ) was used. The weekly food intake of the fish was pre-measured and then we gave them by hand, 3 times a day at 9:00, 12:00 and 16:00. During the experiment, the uneaten feed and fish faeces were removed twice a day with a plastic tube, daily $10 \%$, once a week $50 \%$ water changes were performed. After the water exchange, for the humic acid treatments, the turbidity of the water was adjusted by adding 7-7 $\mathrm{ml}$ of humic acid. At the end of the 28-day experiment, the individual wet body weight and body length of fish were measured individually. The following production parameters were determined:

- Survival of fish: SR (\%) = (number of live fish/ initial number of fish) $* 100$

- Specific growth rate: SGR $(\% /$ day $)=(\ln \mathrm{BWf}-\ln$ BWi) / t x 100, where: Wf: final body weight (g), $\mathrm{Wi}$ : initial body weight $(\mathrm{g})$, $\mathrm{t}$ : number of days

- Feed conversation ratio: FCR (g/g) = F / (Wf-Wi), where: F: feed consumed during the experiment $(\mathrm{g})$, Wf: final body weight $(\mathrm{g}), \mathrm{Wi}$ : initial body weight (g) 
- Condition factor: $\mathrm{C}=\mathrm{W} / \mathrm{L}^{3}$ x 100 , where $\mathrm{W}$ : wet body weight (g), L: standard body length $(\mathrm{mm})$

- Coefficient of variation: CV\% $=\mathrm{SD} / \mathrm{Wf} * 100$, where: $\mathrm{SD}=$ standard deviation, $\mathrm{Wf}$ : final body weight $(\mathrm{g})$

For statistical analyses of the results IBM SPSS software was used. To determine the significant differences one-way ANOVA was performed. The homogeneity of data was checked by Levene-test.

\section{RESULTS AND DISCUSSION}

As shown in the Figure 1, at the end of the experiment, the survival rate was above $90 \%$ in all treatments, the observed mortality caused by cannibalism. In treatments with strong illumination (L, LH) the survival was $100 \%$.

Figure 1 . The survival rate $(\%)$

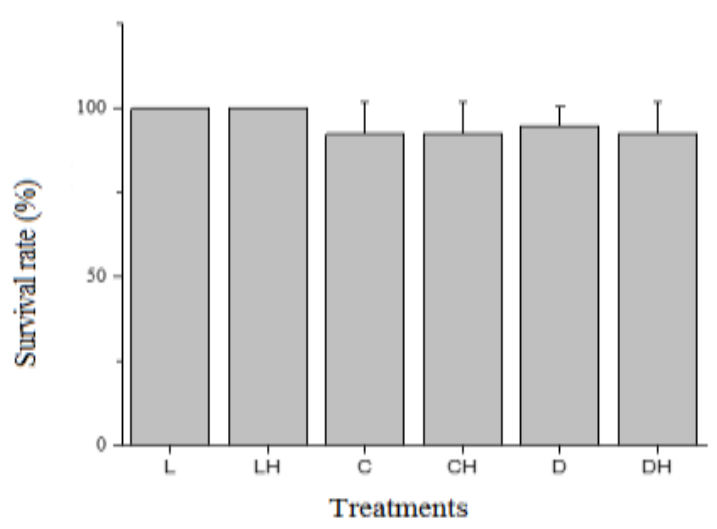

Figure 2 shows the individual body weight of fish after the trial. Considering the final body weight, $\mathrm{C}$ $(4.66 \pm 0.33 \mathrm{~g})$ and $\mathrm{CH}(4.93 \pm 0.15 \mathrm{~g})$ treatments differed significantly from the other treatments except LH. Dark treatments $[(D=3.78 \pm 0.15 g)$; $(D H=3.80 \pm 0.26 \mathrm{~g})]$ achieved the lowest individual weight at the end of the experiment along with the $\mathrm{L}$ group $(3.73 \pm 0.28)$.

As shown in Figure 3, groups C (3.64 1.08$)$ and $\mathrm{CH}(3.74 \pm 1.46)$ achieved significantly higher SGR values at the end of the experiment compared to the group D $(2.86 \pm 1.06), \mathrm{DH}(2.91 \pm 1.05)$ and L $(2.92 \pm 0.70)$. The results of LH treatment $(3.30 \pm 1.22)$ did not differ significantly from the other treatments. The higher weight gain is presumably due to the fish undergoing the least stress in these groups $(\mathrm{C}, \mathrm{CH})$. European Perch prefers vegetative, shady places in terms of their natural habitat, which is also the reason for its striped side, which is the mimic effect. The colour of the water there was probably the most similar to the light conditions preferred by the perch in nature.

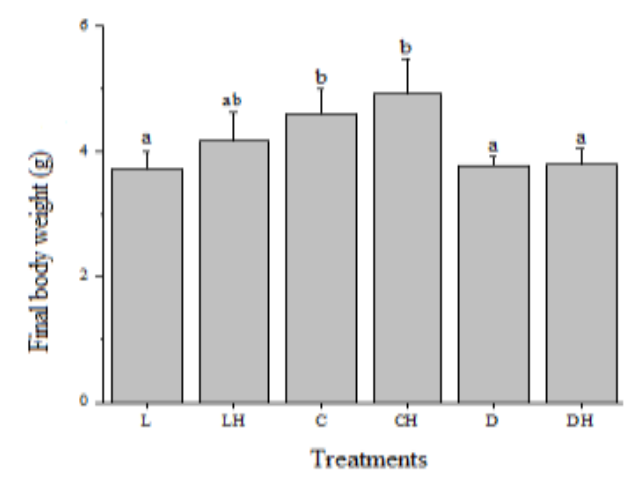

Figure 3. The specific growth rate (SGR \%/day)

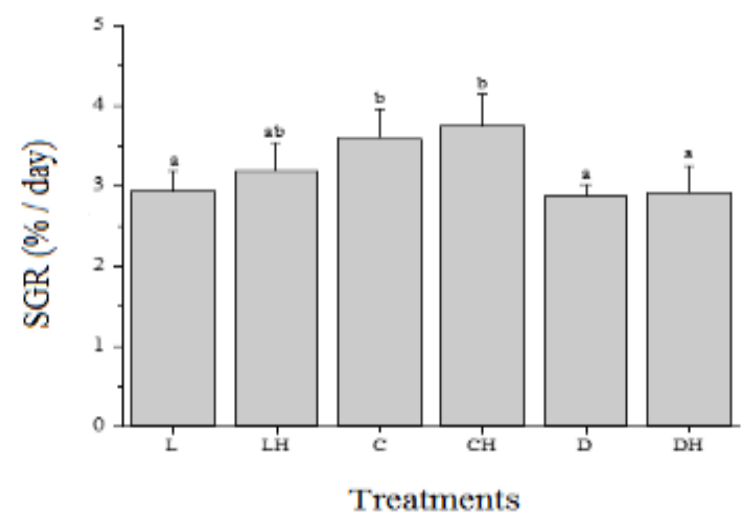

Figure 4. Feed conservation ratio (g/g)

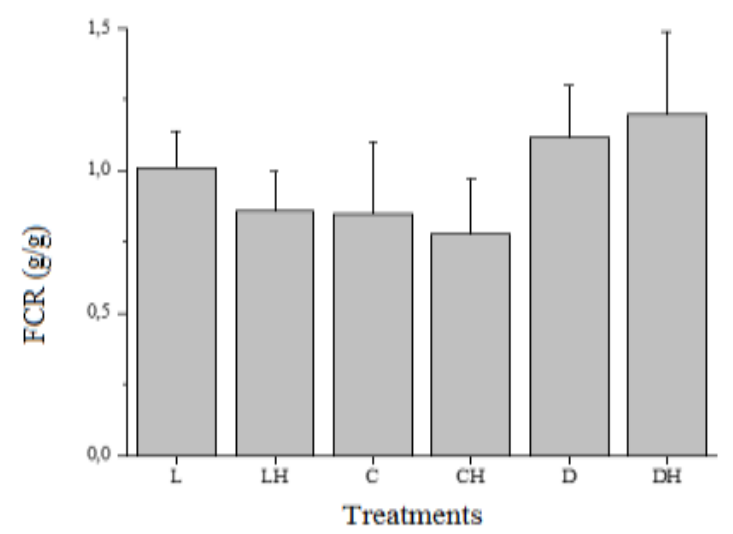

Figure 4 shows the feed conversation ratio (FCR) of treatments at the end of the experiment. Our preconception that the feeding intensity of fish under different light conditions has an impact on production parameters were also confirmed by the results of FCR values at the end of the experiment. At the end of the experiment, the best results were obtained in $\mathrm{C}$ $(0.84 \pm 0.26)$ and $\mathrm{CH}(0.78 \pm 0.19)$ groups even if they 
did not differ significantly from the other treatments. The results of feed conservation ratio are clearly correlated with the other measured production parameters.
The Table 1 shows the condition factor and CV\%. Regarding these indicators, no significant differences were found between treatments.

Table 1. Producing parameters at the end of the experiment

\begin{tabular}{ccccccc}
\hline & L & LH & C & CH & D & DH \\
\hline CV\% initial & $28.26 \pm 7.81$ & $32.89 \pm 1.04$ & $32.51 \pm 11.39$ & $33.06 \pm 6.18$ & $34.48 \pm 14.48$ & $31.11 \pm 18.74$ \\
CV\% final & $18.72 \pm 2.81$ & $29.79 \pm 8.40$ & $24.18 \pm 1.82$ & $29.88 \pm 6.92$ & $27.84 \pm 9.06$ & $27.36 \pm 4.05$ \\
Condition factor & $1.89 \pm 0.37$ & $1.89 \pm 0.52$ & $1.46 \pm 0.16$ & $1.71 \pm 0.36$ & $1.67 \pm 0.12$ & $1.85 \pm 0.49$ \\
\hline
\end{tabular}

\section{CONCLUSIONS}

Overall, based on the scientific literature and the results of the experiment, it can be stated that different light conditions play an important role in the growth and development of fish generally, but the optimal conditions may alter between different species. The results of the production parameters were influenced by the intensity of the illumination and the turbidity of the water, however, their interaction did not affect survival and growth performance. At the end of the experiment the survival was above $90 \%$ regarding all treatments.

The survival of the fish was not affected by either the lighting or the turbidity of the water. The groups receiving $118.0 \pm 24.4$ lux illumination $(\mathrm{C}, \mathrm{CH})$ produced significantly higher individual body weight and growth performance at the end of the experiment compared to the other treatments - however, they did not differ statistically from each other. Humic acid supplementation had the greatest effect on the results in the groups exposed to full light $(\mathrm{L}, \mathrm{LH})$ and had no effect on production parameters in the case of covered treatments $(\mathrm{C}, \mathrm{CH})$ or groups kept in complete darkness (D, DH). There was no statistically differences between groups for FCR. The results of the experiment showed that in the early stages of European perch, neither strong lighting nor complete darkening of the water are recommended, rather moderate lighting has a positive effect on growth and feed conservation ratio, while total darkening has a negative effect on production parameters.

Regarding the individual body weight, the best results were shown in treatments where the aquariums were covered ( $\mathrm{C}: 4.66 \pm 0.33$ grams) and the aquarium water was darkened by the addition of humic acid $(\mathrm{CH}$ : $4.93 \pm 0.15$ grams). The results of the $\mathrm{C}$ and $\mathrm{CH}$ groups were significantly more favorable compared to the other treatments, however, they did not differ statistically from each other. The individual body weight of fish reared in full light was favorably affected by water darkening (L: $3.73 \pm 0.28$ grams; LH: $4.33 \pm 0.28$ grams), whereas in groups reared in the dark, the addition of humic acid did not affect the results (D: $3.78 \pm 0.15$ grams; DH: $3.80 \pm 0.26$ grams).

Similar results were gained by other research groups with European perch juveniles. Similar research was conducted by Tamazouzt et al. (1999). At the end of their experiment, they concluded that during the intensive rearing of perch the application of strong illumination and light tank colours in treatments resulted better production parameters compared to low light conditions and dark tank colours.

The impact of water turbidity on feeding behavior has been demonstrated in other fish species, such as walleye larvae (Stizostedion vitreum) (Bristow et al., 1994). At the end of their experiment they found that there are significant differences in the food intake of walleye larvae reared in clear and turbid water. Their results shown that mean final weight of the walleye larvae from turbid water was 2.25 times greater than larvae reared in clear water. These data differ from our results, however the fish species is also different. Probably this is a specific phenomenon, each fish species respond differently to the colour of the water.

Based on our observations in rearing of European perch juveniles in intensive system must take into consideration of the hectic behavioral, the high sensitivity to stress and the specific environmental needs. Light conditions can easily affect the biorhythm of fish, recommended to set moderate light conditions to avoid deterioration of production parameters. The perch is very sensitive even the lowest light intensity (Brüning et al., 2015).

In order to interpret our results and draw conclusions, it is also worth examining the lifestyle of perch. Due to its lifestyle, it prefers places which densely covered by plants, it can easily hide between them and have moderate light conditions too. Based on the results of our experiment, the light conditions as natural as possible are the most favorable for rearing of European perch in an intensive system.

In the future further researches are needed on this topic for more accurate results. In our opinion could be useful try other environmentally friendly materials for darkening the water as well.

\section{ACKNOWLEDGEMENTS}

The publication is supported by the EFOP-3.6.3VEKOP-16-2017-00008 project. The project is cofinanced by the European Union and the European Social Fund. The work was supported by the MAHOP-2.1.1-2016-2017-00002 (RESEARCHFISH) project. 


\section{REFERENCES}

Acerete, L.-Balasch, J.-Espinosa, E.-Josa, A.-Tort, L. (2004): Physiological responses in Eurasian perch (Perca fluviatilis, L.) subjected to stress by transport and handling. Aquaculture, 237 (1-4), 167-178.

Boeuf, G.-Le Bail, P.Y. (1999): Does light have an influence on fish growth? Aquaculture, 177 (1-4), 129-152.

Bristow, B.T.-Summerfelt, R.C., (1994): Performance of Larval Walleye Cultured Intensively in Clear and Turbid Water. Journal of the World Aquaculture Society, 25(3), 454-464.

Brüning, A.-Hölker, F.-Franke, S.-Kleiner, W.-Kloas, W. (2016) Impact of different colours of artificial light at night on melatonin rhythm and gene expression of gonadotropins in European perch. Science of The Total Environment, 543, 214 222.

Brüning, A.-Hölker, F.-Franke, S.-Preuer, T.-Kloas, W. (2015): Spotlight on fish: Light pollution affects circadian rhythms of European perch but does not cause stress. Science of The Total Environment, 511, 516-522.

Couture, P.-Pyle, G. (2015): Biology of Perch. Crc press: Boca Raton, Florida, 1-7.

Craig, J.F. (1977): Seasonal changes in the day and night activity of adult perch, Perca fluviatilis L. Journal of Fish Biology, 11 (2), 161-166.

Davidson, G.-Thorarensen, H.T.-Lokman, M.-Davie, P.S. (1997) Stress of capture and captivity in kahawai arripis trutta (bloch and schneider) (perciformes: Arripidae). Comparative Biochemistry and Physiology Part A: Physiology, 118 (4):14051410.

Härkönen, L.-Hyvärinen, P.-Mehtätalo, L.-Vainikka, A. (2017) Growth, survival and interspecific social learning in the first hatchery generation of Eurasian perch (Perca fluviatilis). Aquaculture, 466, 64-71.

Haworth, R.D. (1971): The chemical nature of humic acid. Soil Science, 111 (1), 71-79.

Islam, K.M.S.-Schuhmacher, A.-Gropp, J.M. (2005): Humic acid substances in animal agriculture. Pakistan Journal of nutrition, $4(3), 126-134$

Järv, L.-Kotta, J.-Simm, M. (2013): Relationship between biological characteristics of fish and their contamination with trace metals: a case study of perch Perca fluviatilis L. in the Baltic Sea. Proceedings of the Estonian Academy of Sciences, 62(3), 193.
Craig, J.F. (2000): Percid Fishes: Systematics, Ecology, and Exploitation, Fish and Aquatic Resources Series. Blackwell science: Oxford, England, 15-18.

Kerndorff, H.-Schnitzer, M. (1980): Sorption of metals on humic acid. Geochim Cosmochim Acta, 44 (11), 1701-1708.

Lyach, R.-Remr, J. (2019): The effects of environmental factors and fisheries management on recreational catches of perch Perca fluviatilis in the Czech Republic. Aquatic Living Resources, 32, 15 .

Orban, E.-Nevigato, T.-Masci, M.-Di Lena, G.-Casini, I.-Caproni, R.-Gambelli, L.-De Angelis, P.-Rampacci, M. (2007): Nutritional quality and safety of European perch (Perca fluviatilis) from three lakes of Central Italy. Food Chemistry, $100(2), 482-490$.

Pickering, A.D. (1993): Growth and stress in fish production. Aquaculture, 111(1-4), 51-63.

Rupiasih, N.N.-Vidyasagar, P. (2005). A Review: Compositions, Structures, Properties and Applications of Humic Substances. Journal of Advances in Science and Technology. 8. 16-25.

Skov, C.-Jansen, T.-Arlinghaus, R. (2017): 62 years of population dynamics of European perch (Perca fluviatilis) in a mesotrophic lake tracked using angler diaries: The role of commercial fishing, predation and temperature. Fisheries Research, 195, 71-79.

Strand, Å.-Magnhagen, C.-Alanärä, A. (2007a): Effects of repeated disturbances on feed intake, growth rates and energy expenditures of juvenile perch, Perca fluviatilis. Aquaculture, 265(1-4), 163-168.

Strand, A.--Alanärä, A.-Staffan, F.-Magnhagen, C. (2007b): Effects of tank colour and light intensity on feed intake, growth rate and energy expenditure of juvenile Eurasian perch, Perca fluviatilis L. Aquaculture, 272(1-4), 312-318.

Tamazouzt, L.-Chatain, B.-Fontaine, P. (2000): Tank wall colour and light level affect growth and survival of Eurasian perch larvae (Perca fluviatilis L.). Aquaculture, 182(1-2), 85-90.

Tamazouzt, L.-Leray, C.-Escaffre, A.M.-Terver, D. (1998): Effects of food particle size on Perca fluviatilis larval growth. Aquatic Sciences, 60(2), 89-98. 
